\title{
Study on Loss Assessment of Urban Waterlogging and Mitigation Measures
}

\author{
B.N. Su, H. Huang* \& J.L. Zhao \\ Institute of Public Safety Research, Department of Engineering Physics, Tsinghua University, Beijing, China
}

\begin{abstract}
Recently, urban waterlogging caused by sudden heavy rainfall has become a serious problem. In this paper, diffusion wave approximation of Shallow Water Equations is used to simulate urban waterlogging scenarios. A comprehensive loss assessment of waterlogging is done using vulnerability curves. This method is applied to an actual urban area. Two kinds of mitigation measures, including setting up drains and land leveling, are tested and the effects are compared. The results are useful for disaster mitigation plan and management for ur-ban waterlogging.
\end{abstract}

KEYWORD: Urban waterlogging; Scenario simulation; Loss assessment; Disaster mitigation measures

\section{INSTRUCTION}

Recently, as global weather changes, urban waterlogging caused by sudden heavy rainfall becomes a serious problem, posing great threats to people's life and property. Numerical simulation and risk assessment of urban waterlogging is helpful for disaster mitigation measures to be carried out appropriate. In this way, losses can be reduced efficiently.

In this paper, diffusion wave approximation of Shallow Water Equations is used to simulate urban waterlogging scenarios. According to the spatial and temporal distribution of water, a comprehensive loss assessment of waterlogging is done using vulnerability curves. This method is applied to an actual urban area. Two kinds of disaster mitigation measures, including setting up drains and land leveling, are tested and the effects are compared.

\section{METHODS}

\subsection{Waterlogging scenario simulation}

There are many studies on the simulation of flood and waterlogging. Among all kinds of simulation methods, 2D hydraulic methods are wildly used in engineering field, because they achieved a balance between simulation speed and result accuracy. The basic idea of 2D hydraulic methods is solving Shallow Water Equations (SWEs).

Unlike in river floods, water flow is gentle in urban waterlogging. That means the acceleration term in SWEs is negligible. The method of solving SWEs without considering acceleration term is called dif-fusion wave approximation. The governing equations in this paper are SWEs considering rainfall while ignoring acceleration term.

$$
\begin{aligned}
& \frac{\partial d}{\partial t}+\frac{\partial(d u)}{\partial x}+\frac{\partial(d v)}{\partial y}=q \\
& -\frac{\partial h}{\partial x}=\frac{n^{2} u \sqrt{u^{2}+v^{2}}}{k^{2} d^{4 / 3}} \\
& -\frac{\partial h}{\partial y}=\frac{n^{2} v \sqrt{u^{2}+v^{2}}}{k^{2} d^{4 / 3}}
\end{aligned}
$$

Where $d=$ water depth $(\mathrm{m}) ; u=$ water velocity component in $x$ direction $(\mathrm{m} / \mathrm{s}) ; v=$ water velocity component in $y$ direction $(\mathrm{m} / \mathrm{s}) ; h=$ water surface elevation (m), which equals to water depth plus bed elevation; $q=$ rainfall intensity $(\mathrm{m} / \mathrm{s}$, converted from $\mathrm{mm} / \mathrm{h}$ ); $n=$ manning coefficient (dimensionless); and $k=$ conversion factor (constant, $1 \mathrm{~m}^{1 / 3} / \mathrm{s}$ ).

Land infiltration is ignored in this paper since urban land is often covered with impervious materials such as asphalt and concrete. Evaporation is also neglected because evaporation rate is very low when raining.

\subsection{Loss assessment using vulnerability curves}

The spatial and temporal distribution of water can be obtained through numerical simulation. However, to estimate disaster risk, a loss assessment is also 
needed. The bases of loss assessment are vulnerability curves which are established according to survey da-ta. With these curves, losses can be estimated using water depth data. In this paper, waterlogging vulnerability curves based on field investigation was used (Yin, 2011).

\section{CASE STUDIES}

\subsection{Study area}

An actual urban area in Zhenhai District, Ningbo City, Zhejiang Province is selected as the study area. The area is about 3.6 kilometers wide from east to west, 3.2 kilometers long from north to south, has more than 10 square kilometers.

In this paper, rainfall scenarios with different duration (namely 30 minutes, 60 minutes, and 90 minutes) and different return period (namely 5 years, 10 years, 20 years, 50 years, and 100 years) are considered. Rainfall is estimated using data published by Department of Construction of Zhejiang Province (2008), as shown in Table 1.

Table 1. Rainfall under different scenarios in Zhenhai (mm).

\begin{tabular}{|c|c|c|c|}
\hline \multirow{2}{*}{$\begin{array}{c}\text { Return Period } \\
\text { (year) }\end{array}$} & \multicolumn{3}{|c|}{ Duration (min) } \\
\cline { 2 - 4 } & 30 & 60 & 90 \\
\hline 5 & 47 & 63 & 71 \\
\hline 10 & 54 & 73 & 83 \\
\hline 20 & 62 & 83 & 94 \\
\hline 50 & 71 & 96 & 108 \\
\hline 100 & 79 & 106 & 119 \\
\hline
\end{tabular}

\subsection{Loss estimation of rainfall scenarios}

All the 15 rainfall scenarios are simulated. The spatial distributions of maximum water depth during the rain are calculated. Example distribution of maxi-mum water depth is shown in Figure 1.

It can be seen that waterlogging often occurs at same place under different rainfall scenarios.

With the vulnerability curves, the spatial distributions of economic losses are also estimated. Total losses can be easily obtained by sum the losses over the whole map. Maximum water depth and total economic losses under different rainfall scenarios are shown in Figure 2 and Figure 3.

It can be seen that rains with longer durations and longer return period can cause more serious waterlogging and greater economic losses.

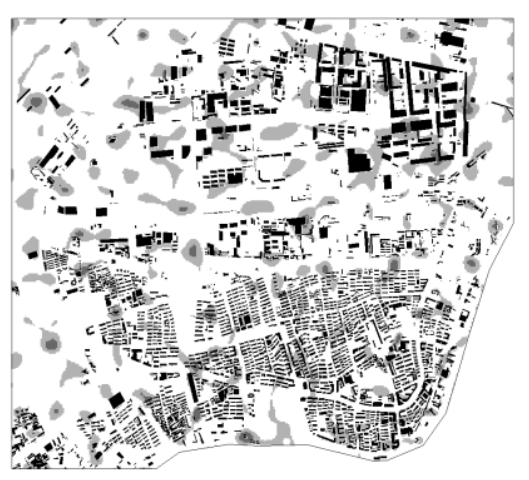

(a) 60 min rain, 5 years return period
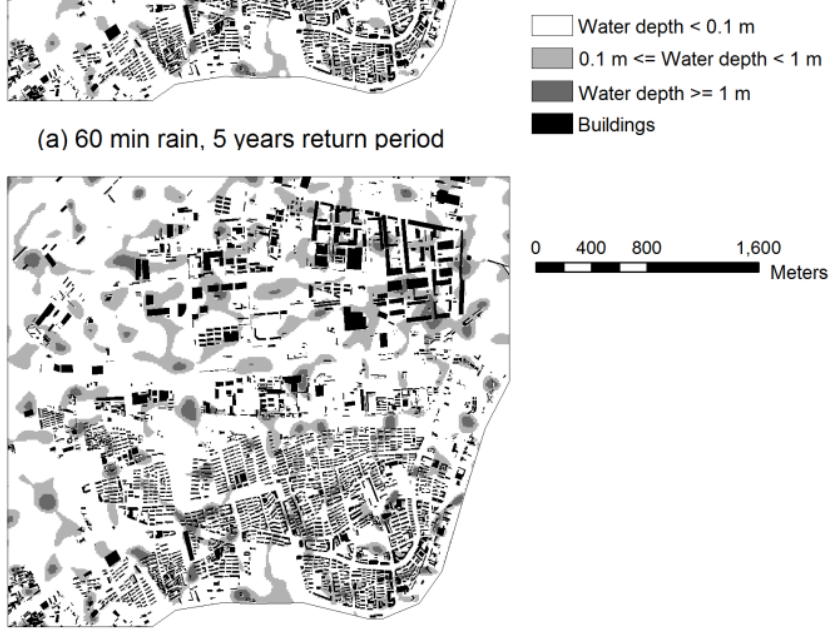

(b) 60 min rain, 100 years return period

Figure 1. Example distribution of maximum water depth.

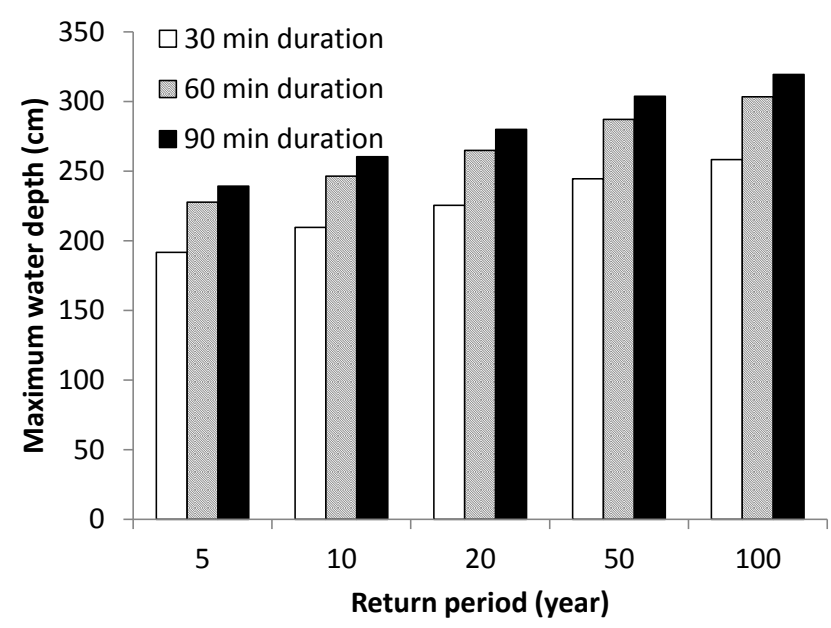

Figure 2. Maximum water depth under different scenarios.

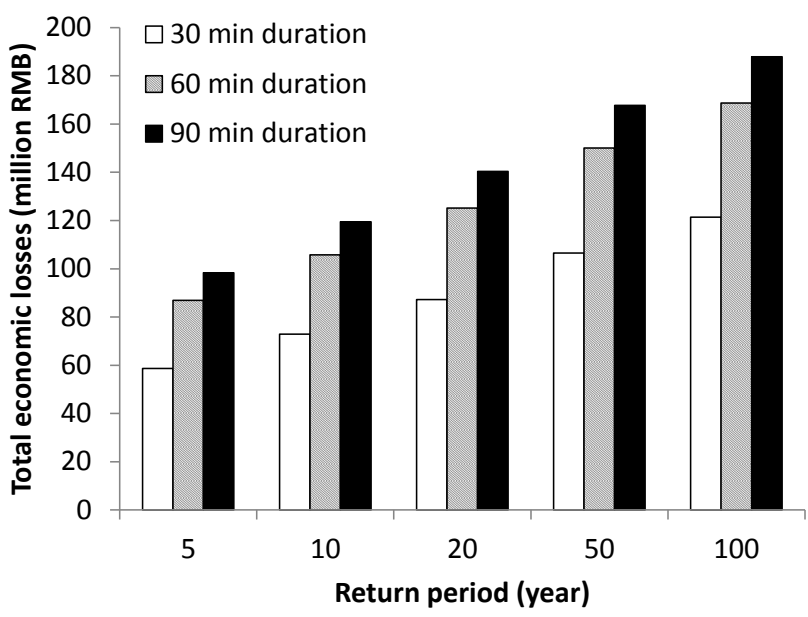

Figure 3. Total economic losses under different scenarios. 


\subsection{Effect of disaster mitigation measures}

Nowadays, drains are widely used as a disaster mitigation measure for flood and waterlogging in urban areas.

In this paper, drains' capabilities are modeled using following equation.

$$
Q=C A \sqrt{g d}
$$

Where $Q=$ discharge rate $\left(\mathrm{m}^{3} / \mathrm{s}\right) ; C=$ discharge coefficient (dimensionless); $A=$ cross section of drain $\left(\mathrm{m}^{2}\right) ; g=$ gravity constant (constant, $9.8 \mathrm{~m} / \mathrm{s}^{2}$ ); and $d=$ water depth above the drain $(\mathrm{m})$.

In this paper, three hypothetical distributions (grid with $20 \mathrm{~m}$ interval, grid with $40 \mathrm{~m}$ interval, and grid with $60 \mathrm{~m}$ interval) are considered.

Take rains with 100 years return period as example, the effect of drains on reducing maximum water depth and total economic losses are shown in Figure 4 and Figure 5.

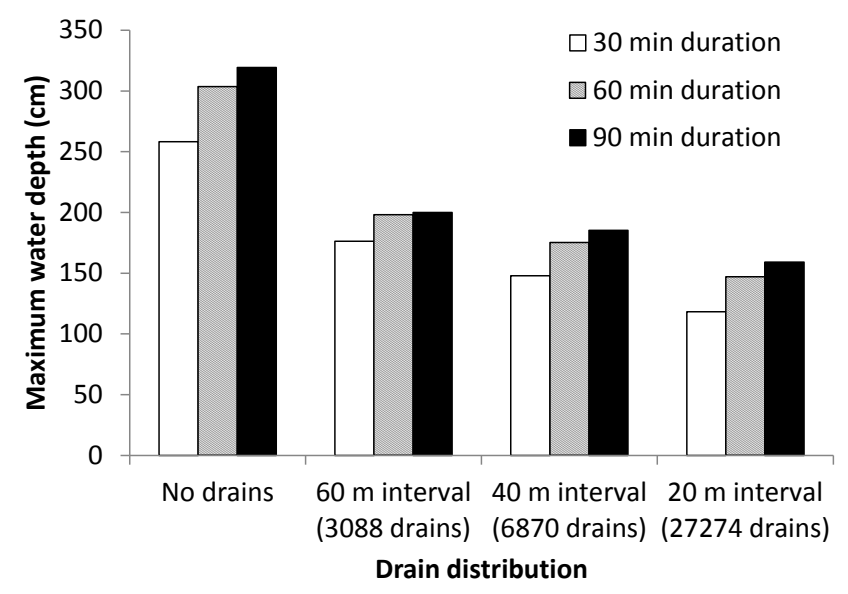

Figure 4. Maximum water depth with different drain distributions.

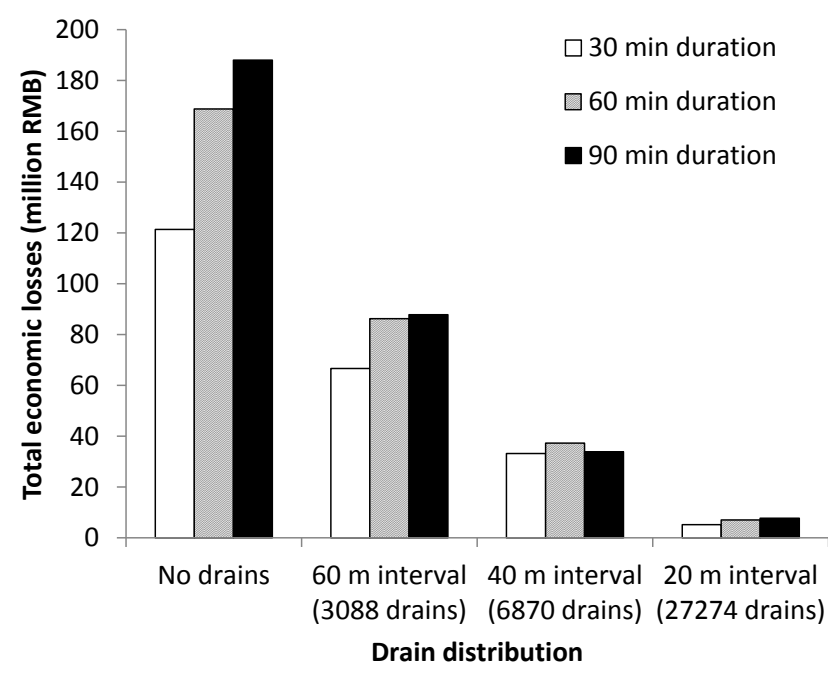

Figure 5. Total economic losses with different drain distributions.

It is clear that with more drains set up, both maximum water depth and total economic losses will decrease significantly. However, the cost of drainage system also increases as the number of drains in-creases. Figure 6 shows the average contribution on reducing losses of each drain.

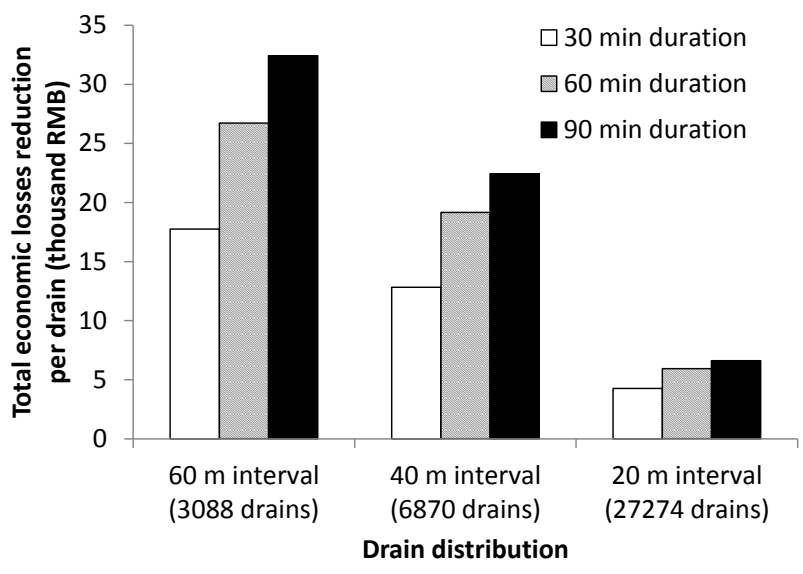

Figure 6. Average contribution on reducing losses of each drain.

It can be seen that as the number of drains increases, the average return from every addition drain drops. That means increasing the number of drains blindly is economically unreasonable. The relation between cost and benefit should be studied and used to make actual plans.

From Figure 5 and 6, we can also find that setting up drains has much better effect on long-lasting rains than short-lasting rains. That is because drains with same drainage capability can drain more water as time du-ration increases.

Landscape is very important to the evolution of flood and waterlogging. That means land leveling can be a potential disaster mitigation measure.

In this paper, three hypothetical plans of land leveling (reducing land slope to $75 \%$, reducing land slope to 50\%, and completely leveling) are considered. The earthwork volumes needed to complete these plans are shown in Table 2.

Table 2. Earthwork volumes needed by different plans.

\begin{tabular}{|c|c|}
\hline Plan & $\begin{array}{c}\text { Earthwork volume needed } \\
\left(\text { million } \mathrm{m}^{3}\right)\end{array}$ \\
\hline $100 \%$ slope (no leveling) & 0 \\
\hline $75 \%$ slope & 7.0 \\
\hline $50 \%$ slope & 13.6 \\
\hline $0 \%$ slope (completely leveling) & 26.0 \\
\hline
\end{tabular}

Take rains with 100 years return period as example, the effect of land leveling on reducing maximum water depth and total economic losses are shown in Figure 7 and Figure 8.

As the scale of land leveling increases, maximum water depth and total economic losses will decrease. If the land is completely flat, the maximum water depth can be reduced to a very low level that is lower than threshold value, meaning that there will be no economic losses. Figure 9 shows the average contribution on reducing losses of each cubic meter of earthwork. 


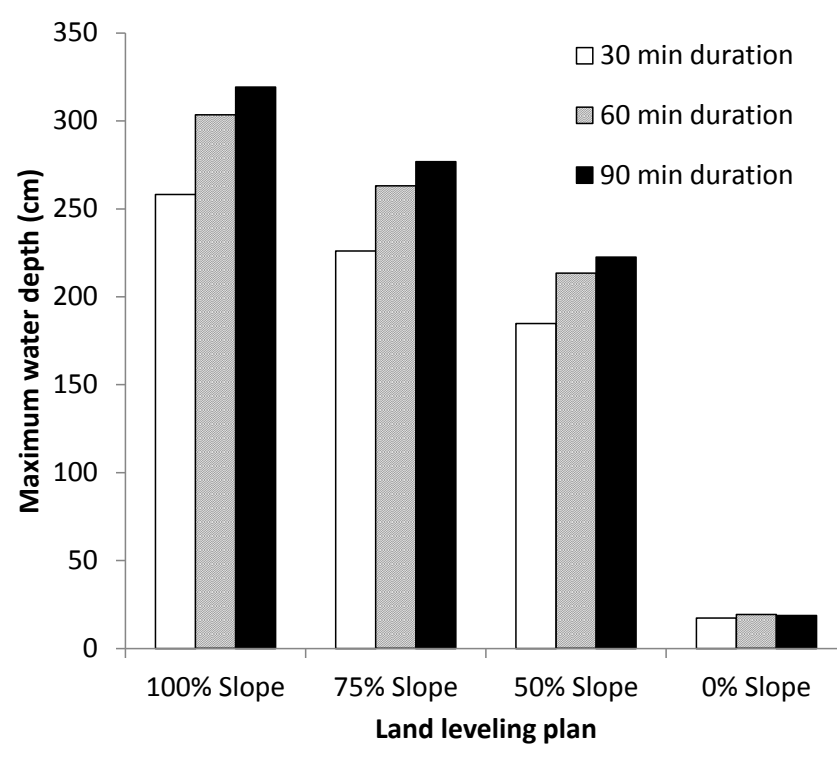

Figure 7. Maximum water depth with different land leveling plan.

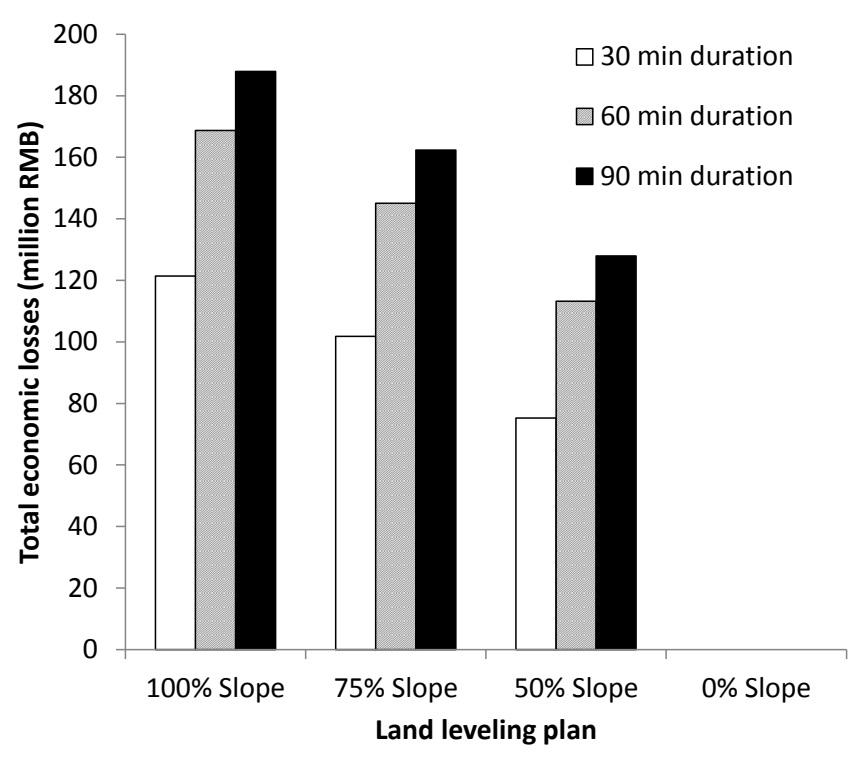

Figure 8. Total economic losses with different land leveling plan.

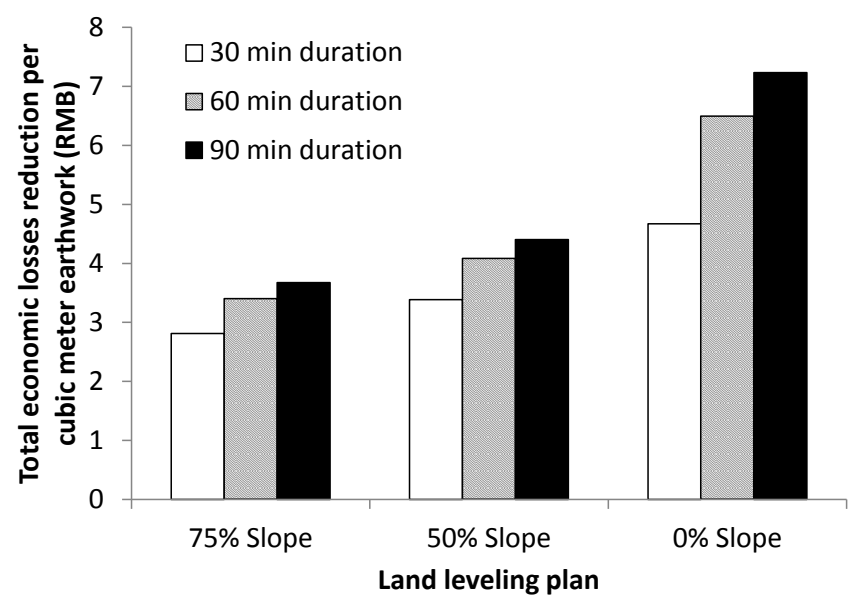

Figure 9. Average contribution on reducing losses of each cubic meter of earthwork.
It is interesting that as the scale of land leveling increases, the average contribution on reducing losses of each cubic meter of earthwork also increases, which is completely contrast to the case of setting up drains. In other words, small scale land leveling has little effect while large scale land leveling is more "worthy".

Although large scale land leveling can achieve good effect on reducing losses, it is very hard to realize in existing cities due to the great cost of reconstruction of buildings and infrastructures. However, Land leveling can be done before new cities or towns are constructed to improve the overall capacity of defending flood and waterlogging.

\section{DISCUSSION AND CONCLUSION}

In this paper, different rainfall scenarios are simulated in an actual urban area. The distribution of water and economic losses are obtained and compared. Two kinds of disaster mitigation measures, including setting up drains and land leveling, are also tested. Some useful relationships are discovered. However, other methods can also be useful. For example, local disaster mitigation measures may be more efficient than overall measures, since water logging often occurs at same place under different rainfall scenarios. Also, different kinds of measures can be used at same time. For example, set up drains after land leveling may be a good plan. In practice, disaster mitigation plans should be made properly according to local conditions.

\section{ACKNOWLEDGEMENT}

This work was supported by the National Natural Science Foundation of China under (Grant No. 71173128) and the Ministry of Science and Technology of the People's Republic of China under Grant No. 2011BAK07B02.

\section{REFERENCES}

[1] Department of Construction of Zhejiang Province. 2008. Formula Table of rainstorm intensity for cities in Zhejiang Province.

http://www.zjjs.com.cn/jsxx/file/2008041801.doc. (in Chinese)

[2] Yin, Z.E., YIN, J., et al. 2011. Community-based scenario modelling and disaster risk assessment of urban rainstorm waterlogging. Journal of Geographical Sciences, 21(2), 274-284. 